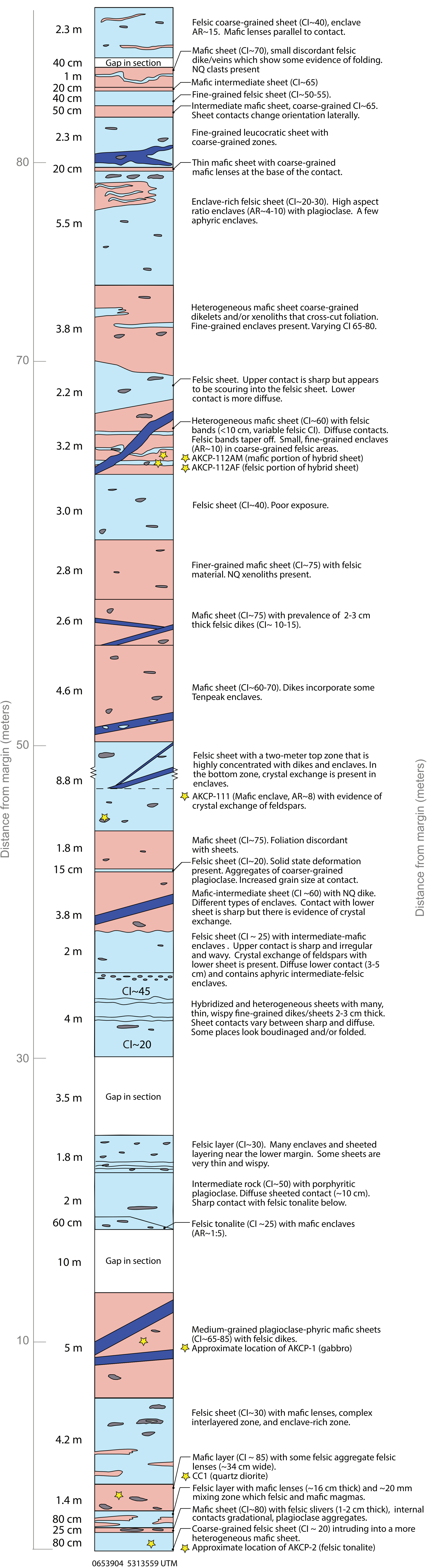

\section{Bottom of section}

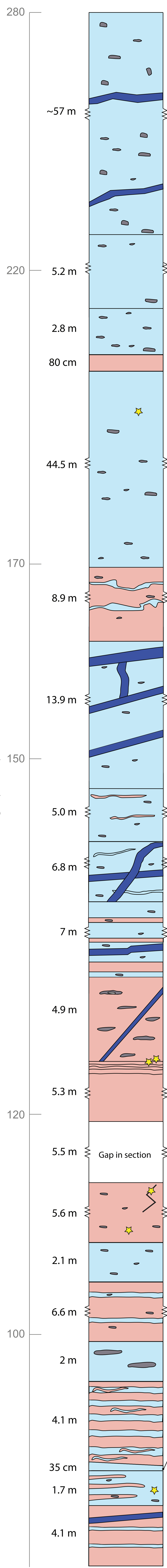

Enclave-rich felsic rock (II $25-40)$ cut by many
sheared No. Gradational contact with overlying

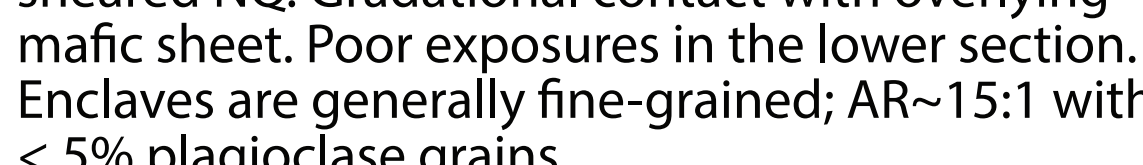

Potential upper graditional contact. Becoming more fisici-intermediate (CI varies from
30-70\%) in irregular zones.

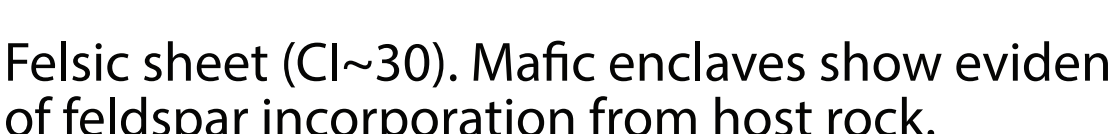
Mafic sheet (CI 65),

Coarse-grained felsic sheet (CI $30-35)$, mostly
homogeneous.

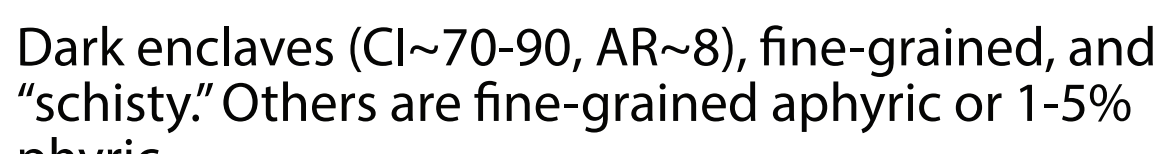
AKCP-118 ffelsic tonalite

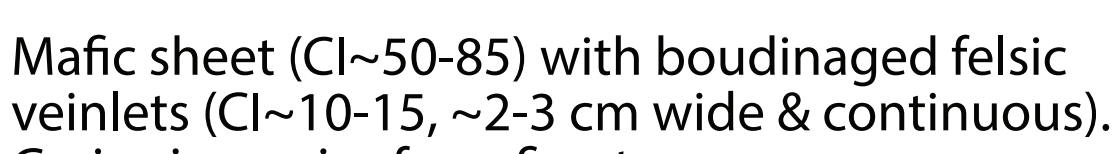

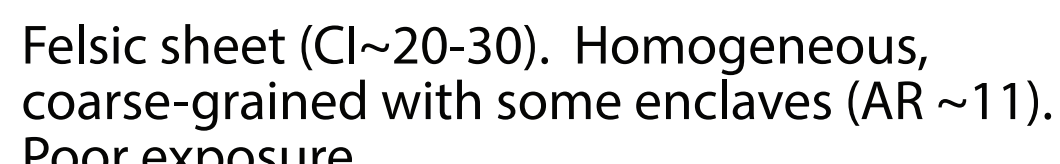

Felsic layer (I 125$)$ with grey, fine-grained enclaves/sheets that incorporate tonalite and
plagioclase xenocrysts. Sharp lower contact.

Intermediate sheet (CI-55-60). Aphyric enclaves Intermediate sheet (CI I55-60). Aphyric enclaves
and some felsic veinlets.

Felsis sheet (CI 25-30). Some enclaves have 5\%
placioclase crystals sand possible interfingering of plagioclase crystals and possible interfingering
mafic and felsic sheeets. Gradational upper

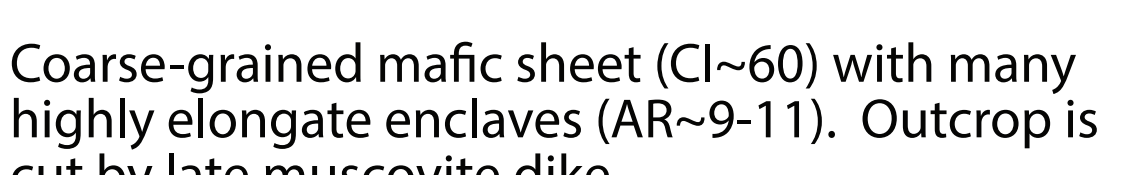
AKCP-115AF (coarse-grained mafic tonalite; s. sampled across contacti) Mafic unit (CI - 85) becomes more feldspar-rich as
you

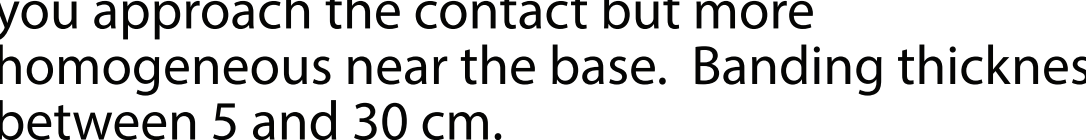

Mafic sheet (II - - 60) with ladder dike (appears
sheared into multiple discs that form a"ladder

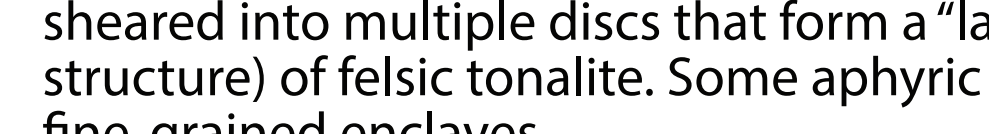
fine-grained enclaves.
AKCP-114 (Felsic ladder dike) A CCEAA (mafic tonalite)

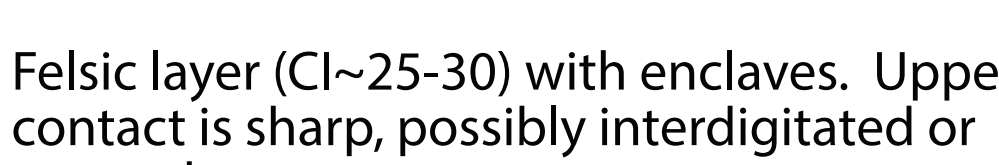
contactis
scoured.

Heterogeneous zone/banding (C 1 - 70-85) with fine-grained enclaves. Some discordant fitsis
layers. Upper contact is gradational.

Felsic sheet with large enclaves (AR 7-14).

Highly heterogeneous sheeted zone/banding

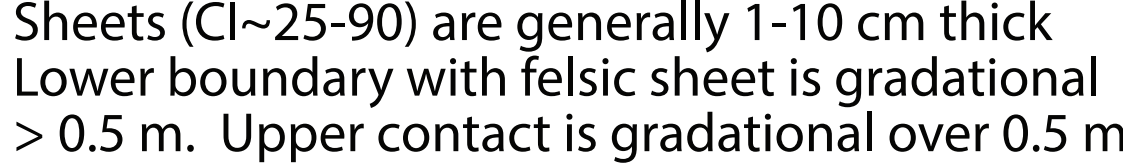
Felsis sheet (CI 25-30) with a sharp contact. Some

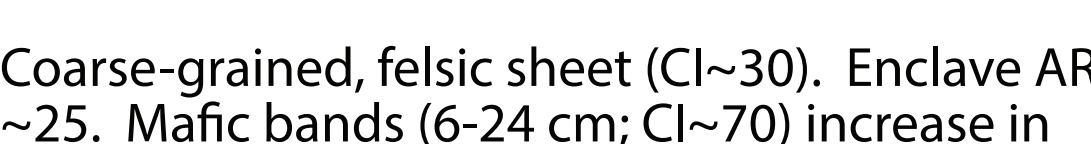
thickness but decrease in plagioclasc upe-section

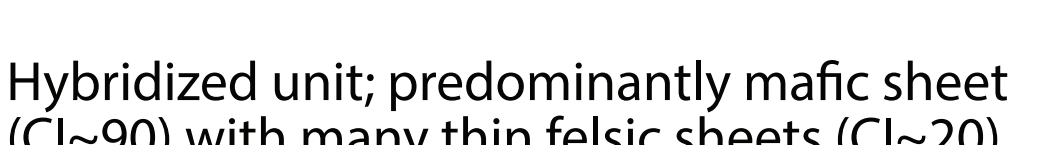

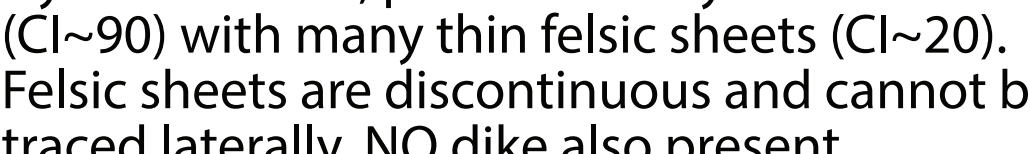

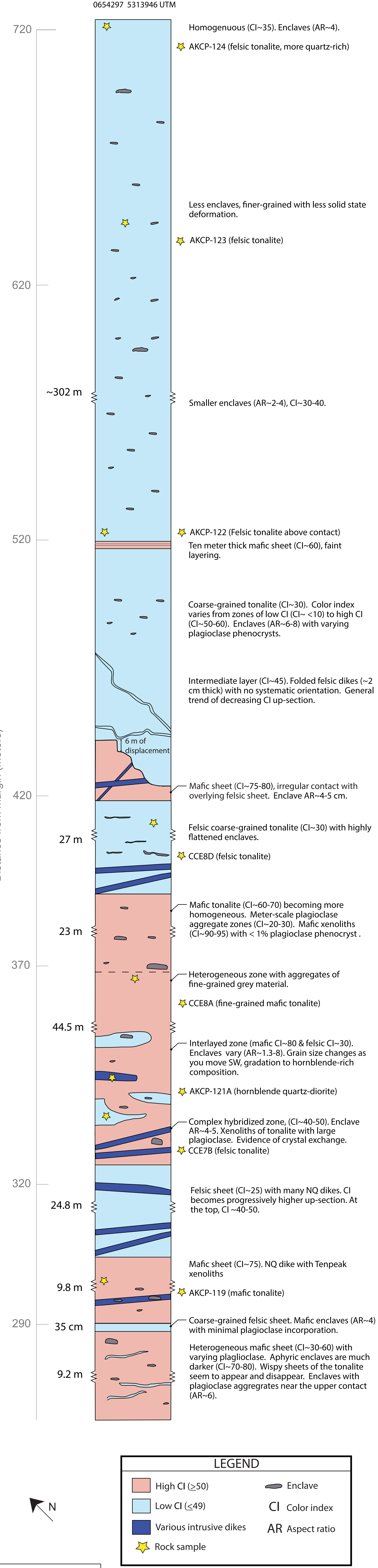

Top of section 
Figure S2: Cathodoluminescence imaging of zircon crystal mounts performed on the JEOL 733 Superprobe electron microprobe at MIT (Cambridge, MA). Image analysis was carried out with a $15 \mathrm{kV}$ accelerating voltage and 10-30 nA beam current. In some samples, zircons were too small to be both imaged and dated. In these cases, representative crystals were selected for imaging. All zircon images are grouped by sample number. Asterisk indicates dated zircon grain.
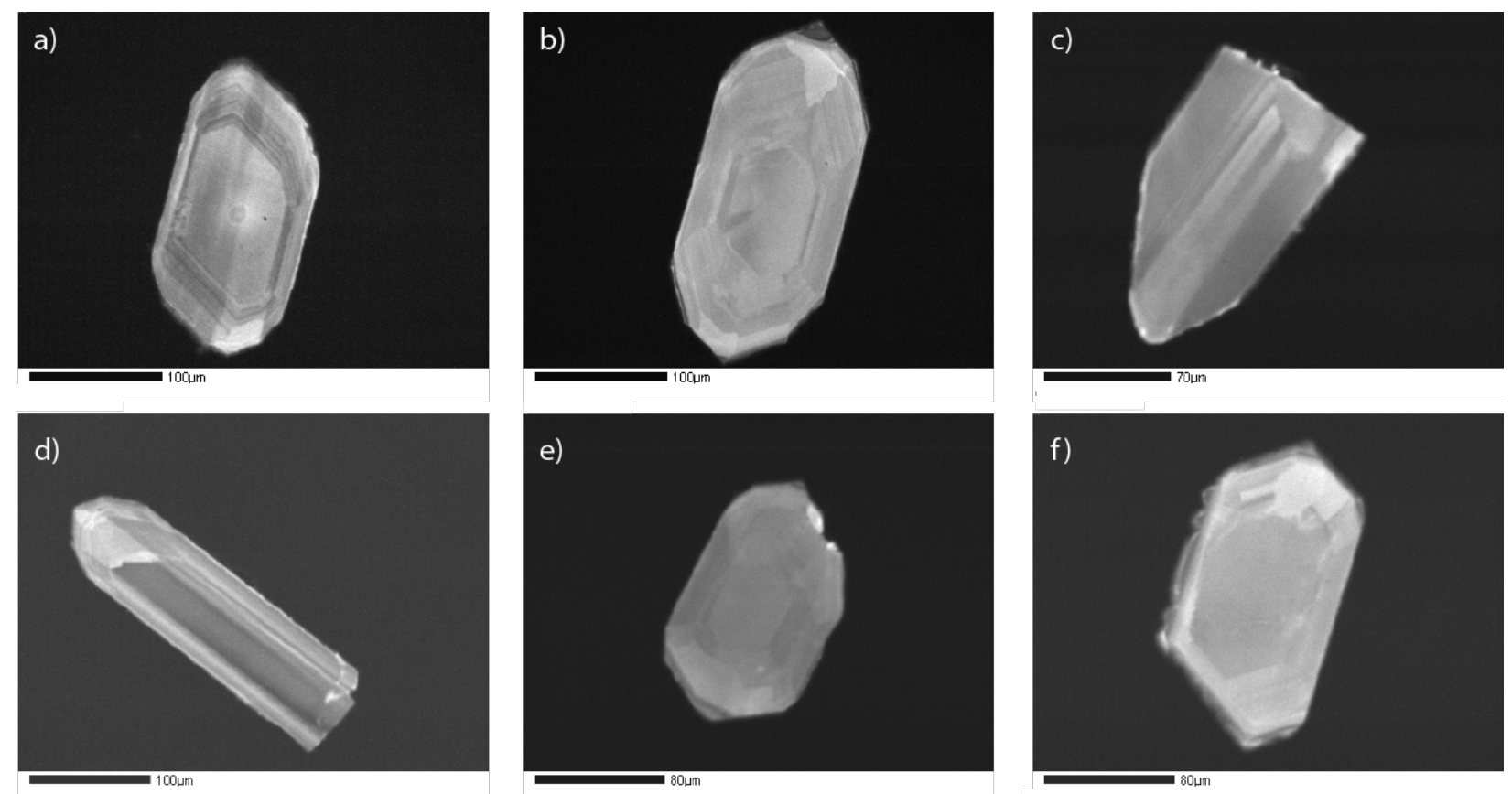

Figure 2A: CL images of dated zircons from sample AKCP-114-a) zL2*b) zL3* c) zM2* d) zM5* e) zM6* f) zM10*. AKCP-114 was collected from a felsic tonalite, coarse-grained ladder dike that appears sheared into multiple discs that form a "ladder" structure (Figure 3G) intruding into a plagioclase-phyric mafic layer (CI 50-60). The dike is likely connected at the base to a lower felsic sheet. Zircons from AKCP-114 are colorless and clear with euhedral equant morphology. CL images of dated and representative crystals show light-colored homogeneous cores with oscillatory-zoned rims. Sector zoning is present in some crystals. Imaged zircons show little evidence for xenocrystic cores - there is no evidence for resorption, textural discontinuities, or large differences in CL characteristics. 

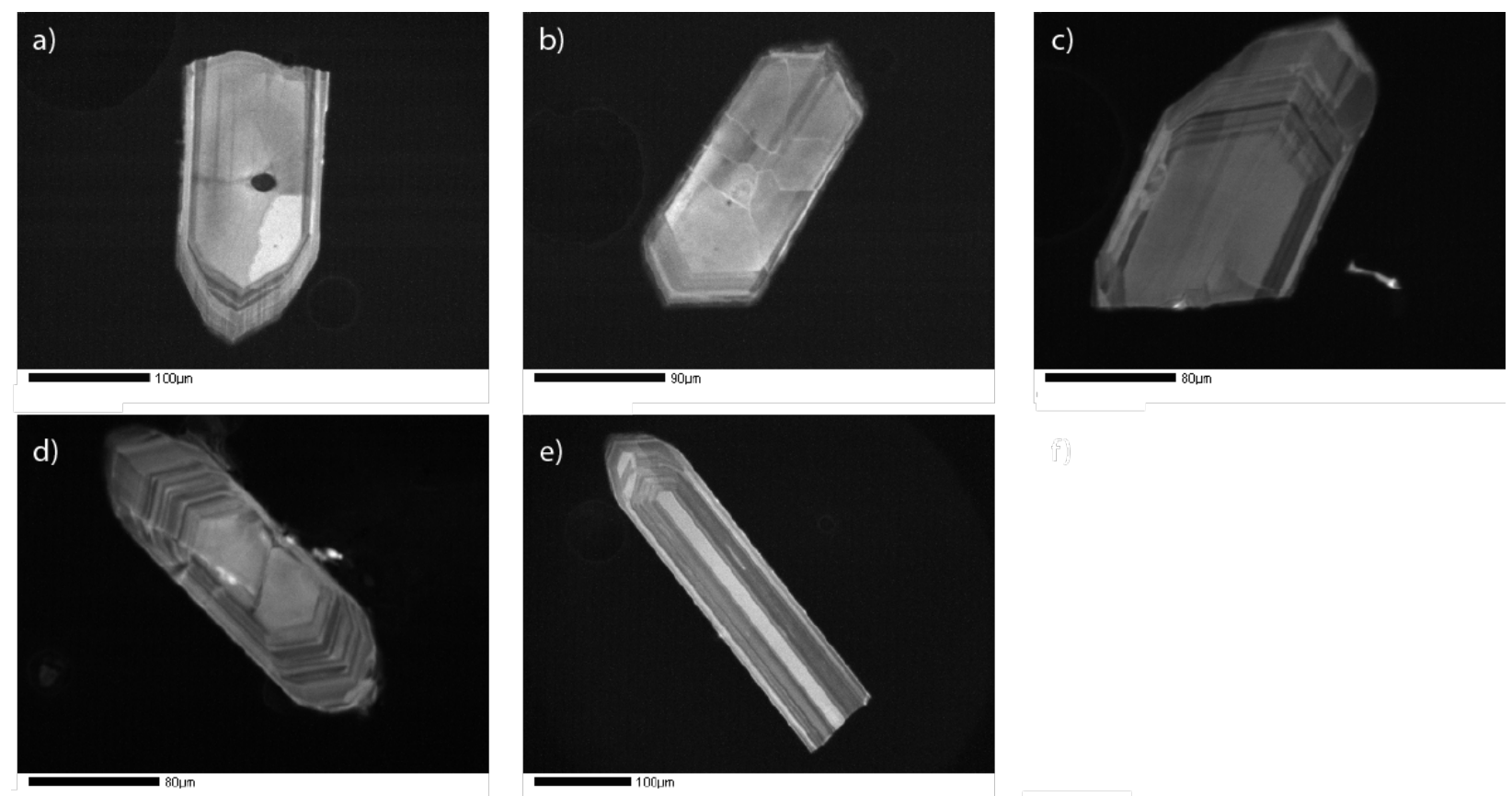

Figure 2B: CL images of dated zircons from sample CCE7B-a) zL3* b) zL4* c) zM4* d) zM7A* e) zM11*. This sample was collected from a $~ 25 \mathrm{~m}$ thick, medium-grained, felsic tonalite sheet (CI 15-25). Zircons from CCE7B are euhedral, squat, colorless, and clear. CL images of dated and representative crystals have light-colored homogeneous cores surrounded by thinner oscillatory-zoned rims. Xenocrystic cores and obviously younger rims are not present in imaged zircons.
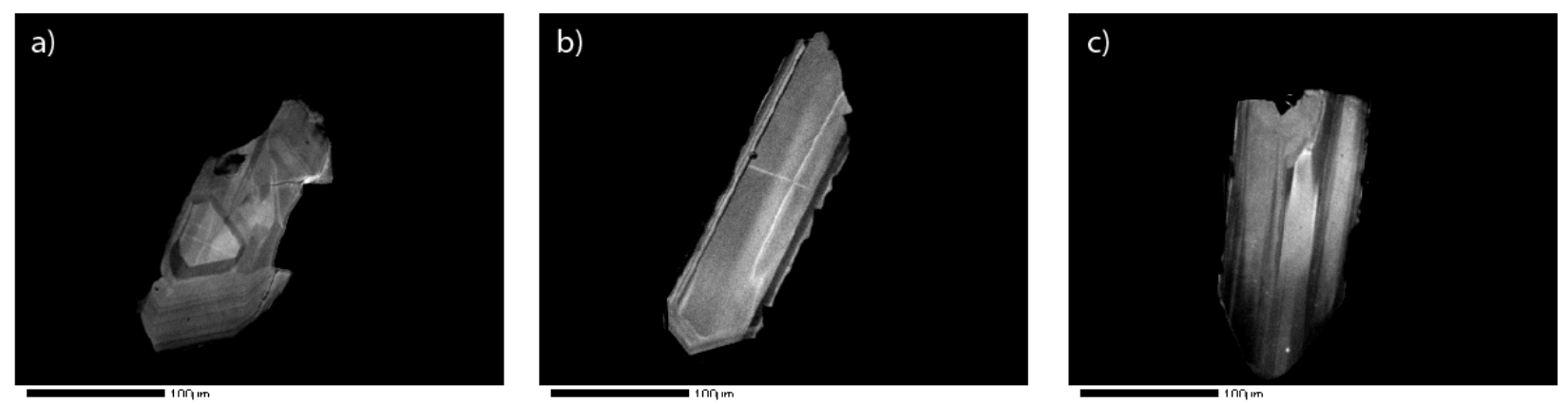

Figure 2C: CL images of representative zircons from sample CC1-a) zM1 b) zM3 c) zM4. CC1 was collected from a $1.4 \mathrm{~m}$ thick mafic sheet (CI 85) less than three meters from the bottom of the sheeted complex transect (Figure 2). This layer contains multiple felsic lenses, the largest of which is $\sim 34 \mathrm{~cm}$ wide. CL images of representative zircons indicate that many crystals are elongate with no evidence for xenocrystic cores or younger rims. Crystals are typically oscillatory-zoned. 

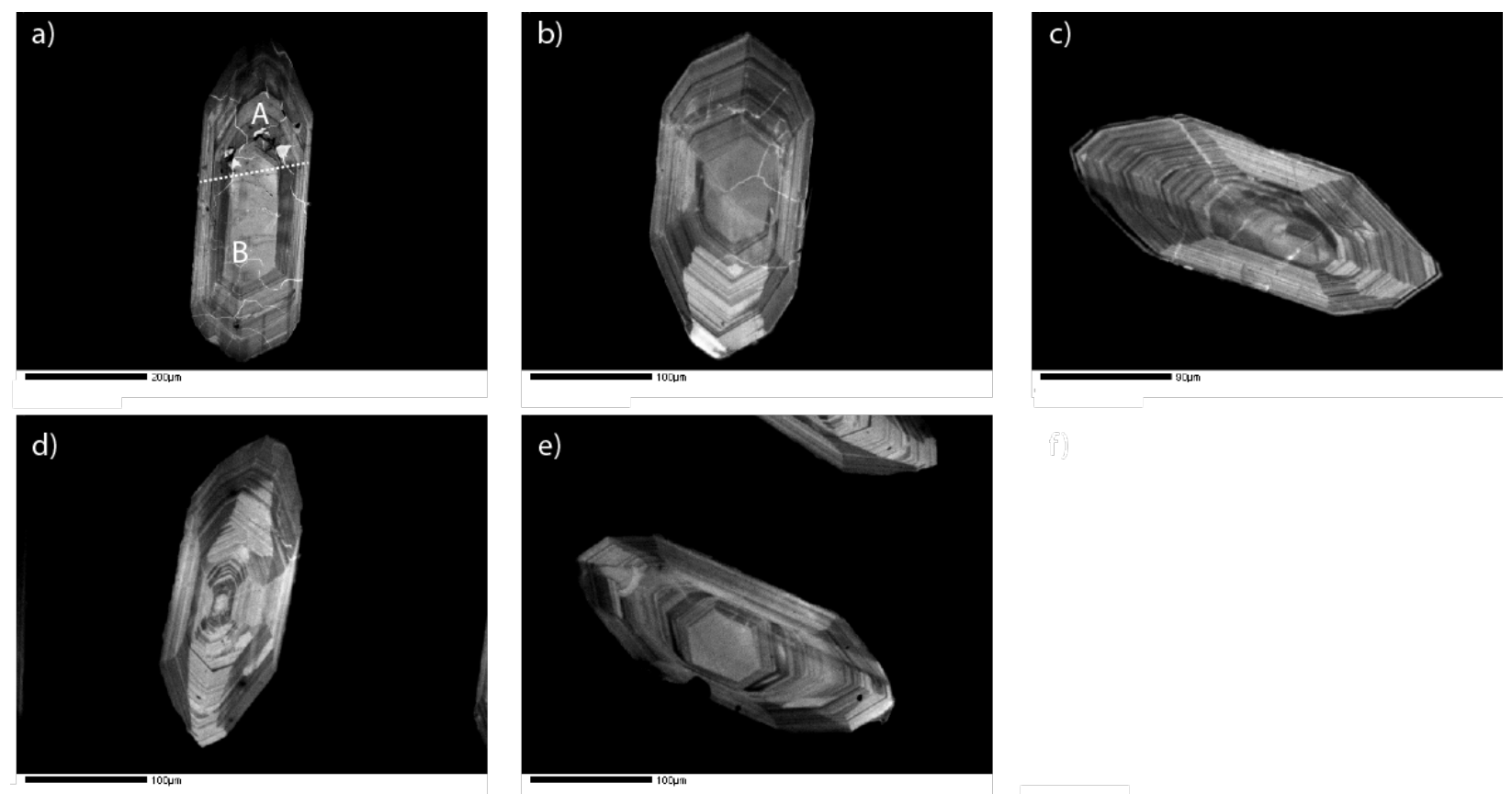

Figure 2D: CL images of dated and representative zircons from sample AKCP-124-a) zL1A, zL1B* b) zL9 c) zL11 d) zM4* e) zM5. AKCP-124 was collected from a 300 m thick, felsic tonalite sheet at the top of the measured section. Zircons from AKCP-124 are colorless, clear, squat or equant euhedral crystals. CL images of dated and representative crystals show small, homogeneous cores surrounded by oscillatory-zoned rims that comprise 50-60\% of the crystal. Sector zoning is present in some crystals. 

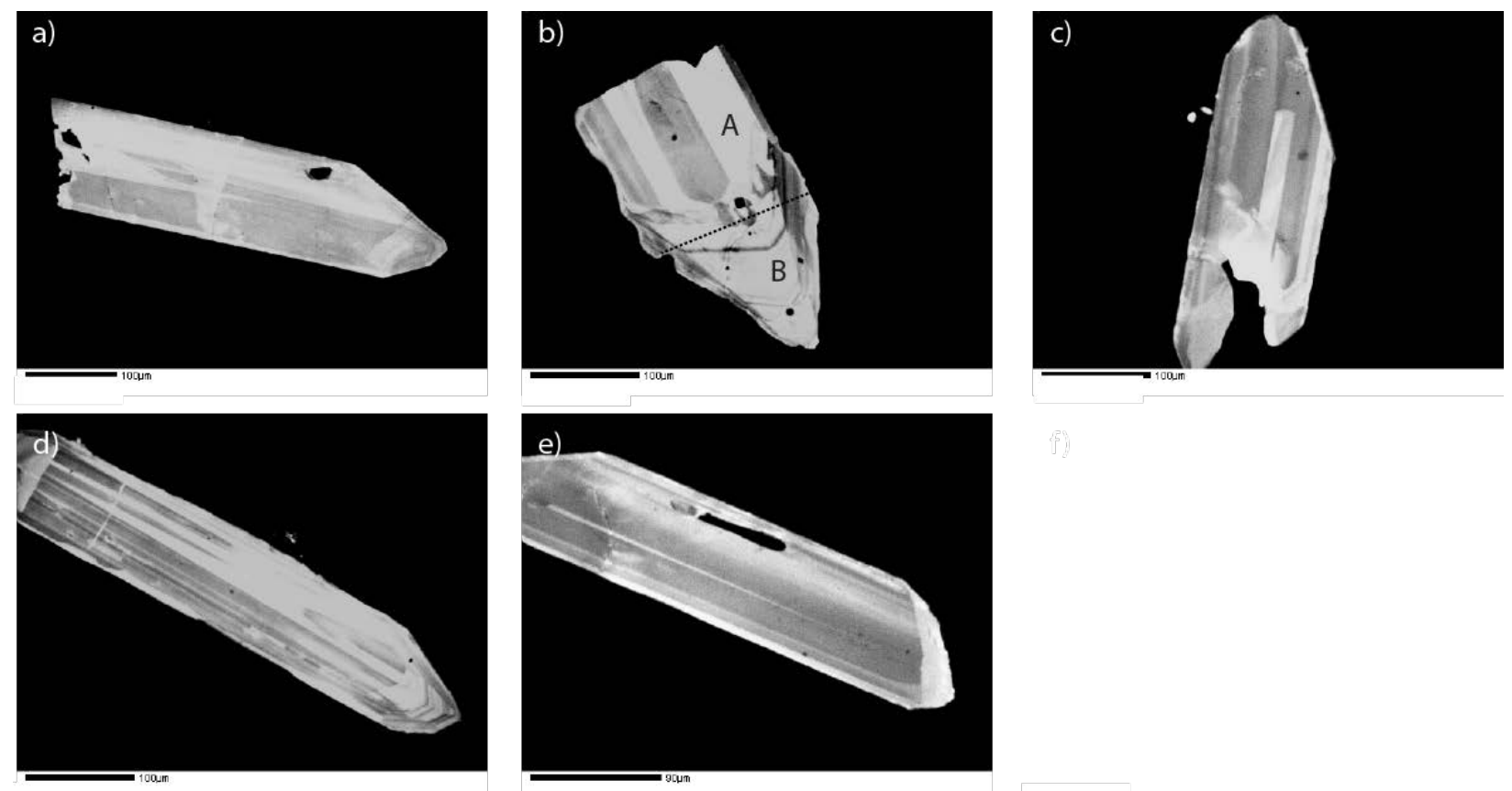

Figure 2E: CL images of dated and representative zircons from sample AKCP-1-a) zL1* b) zL2A*, zL2B c) zM1* d) zM2* e) zS1*. AKCP-1 was collected from a medium-grained, plagioclase-phyric diorite sheet ( $5 \mathrm{~m}$ thick) located $\sim 10$-m above sample AKCP-2. Color index in this layer varied from 65-80 and several coarse-grained dikes/xenoliths cross-cut the foliation. Zircons from AKCP-1 are colorless, clear, euhedral equant or elongate crystals. CL images of dated and representative crystals show zircons with oscillatory-zoned rims surrounding lightcolored cores. Obvious xenocrystic cores are not present.
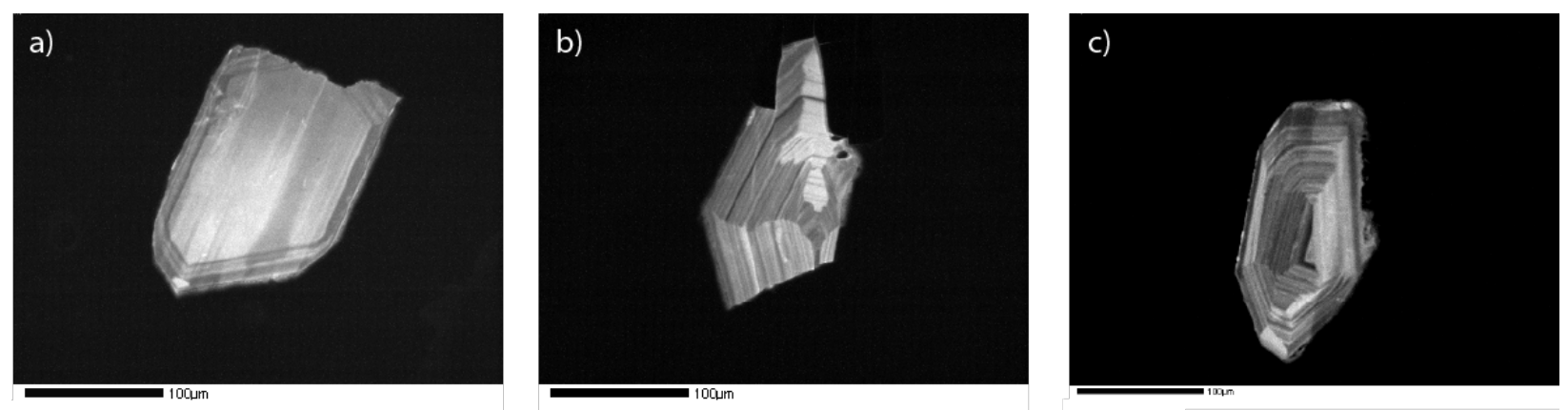

Figure 2F: CL images of dated zircons from sample CCE8D—a) zL2*b) zL4* c) zM1*. CCE8D was collected from a $\sim 27 \mathrm{~m}$ thick felsic tonalite layer (CI 30) with many flattened mafic enclaves. Zircons from CCE8D are colorless, clear, squat or equant euhedral crystals. CL images of representative and dated crystals show large homogeneous cores (up to $~ 90 \%$ of the crystal) surrounded by thin, oscillatory-zoned rims. 

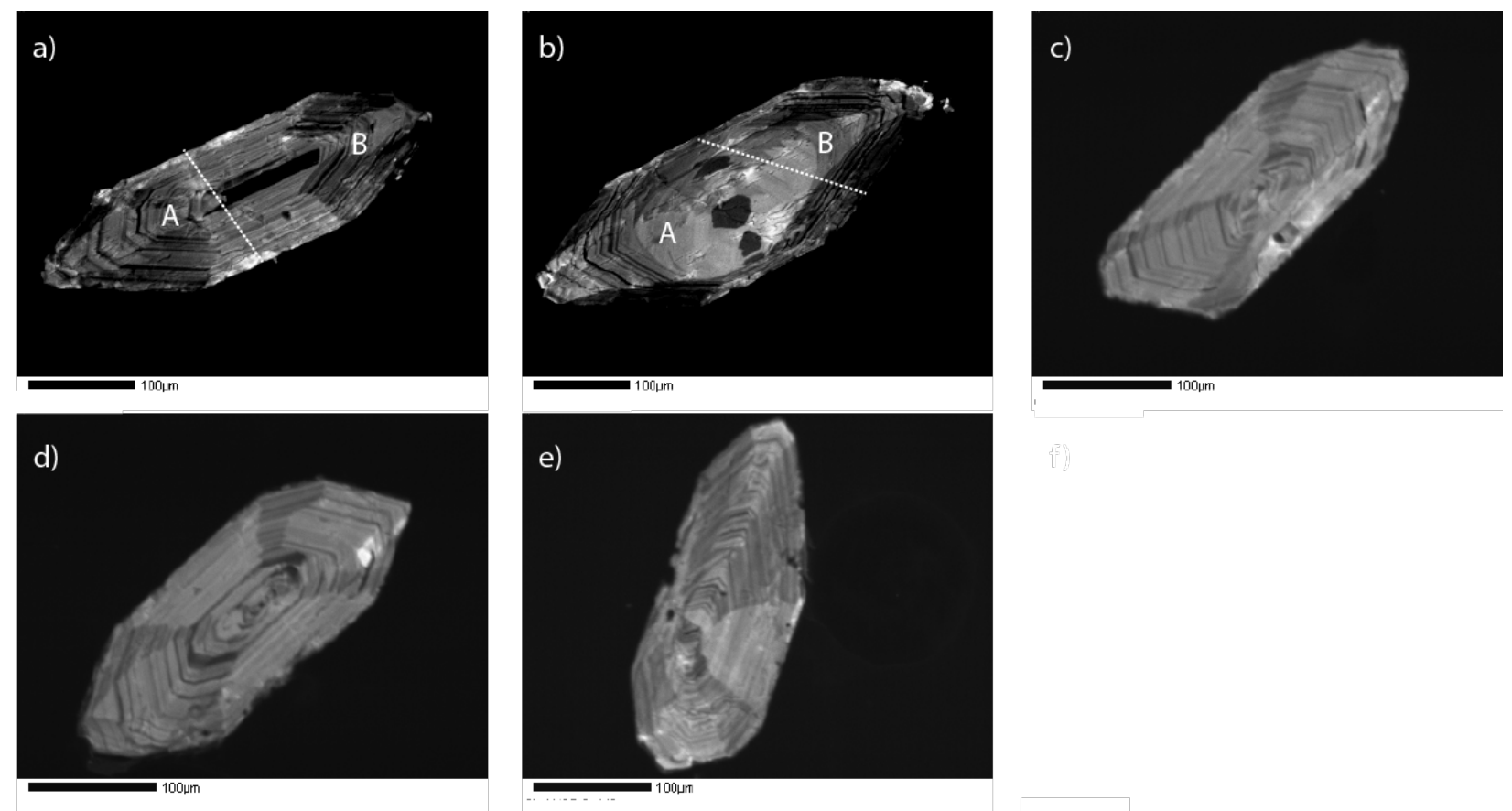

Figure 2G: CL images of dated and representative zircons from sample AKCP-2. Asterisk indicates dated grain. a) zL1A*, zL1B* b) zL2A*, zL2B* c) zM3* d) zM4 e) zM5. AKCP-2 was collected from a $\sim 1 \mathrm{~m}$ thick coarse-grained, felsic tonalite sheet intruded into a heterogeneous mafic layer. CL images of representative crystals suggest there are structural cores, but analysis of rims and cores does not indicate any statistically significant difference in age. Cores are generally small and surrounded by oscillatory-zoned rims that make up most of the crystal. 

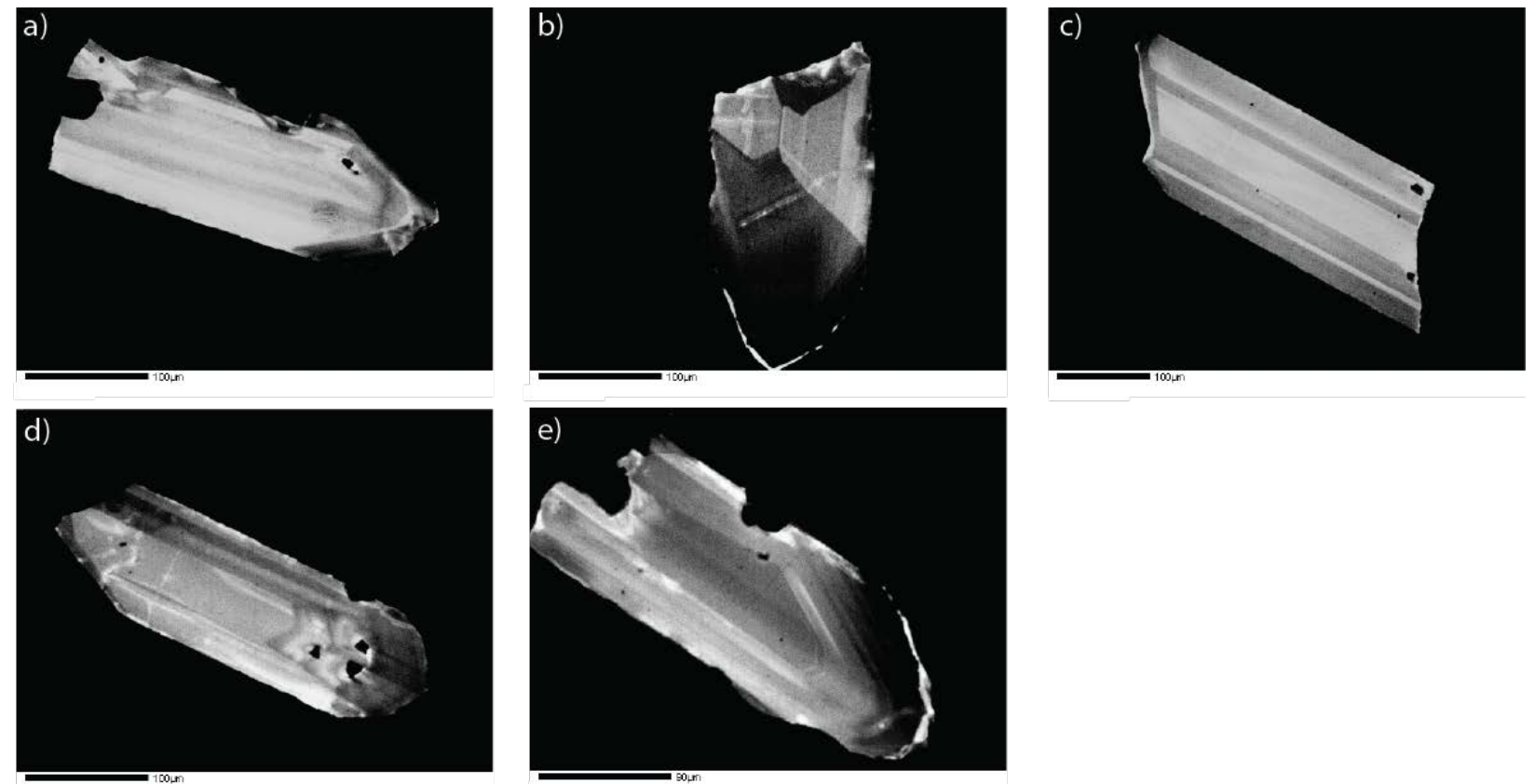

Figure 2H: CL images of dated zircons from sample CCE8A. Asterisk indicates dated grain. a) zL2* b) zL3* c) zL4A* d) zM2* e) zM3*. CCE8A was collected from a fine-grained, mafic, 1 $\mathrm{m}$ thick tonalite dike cross-cutting a $\sim 80 \mathrm{~m}$ thick intrusion of plagioclase-porphyritic tonalite. Minor assimilation of host rock material is observed at the margins of the dike. Zircons are colorless, clear, elongate or equant euhedral crystals. CL imaging reveals oscillatory zoning is common, sometimes with very thin rims on the outer margin of crystals. 

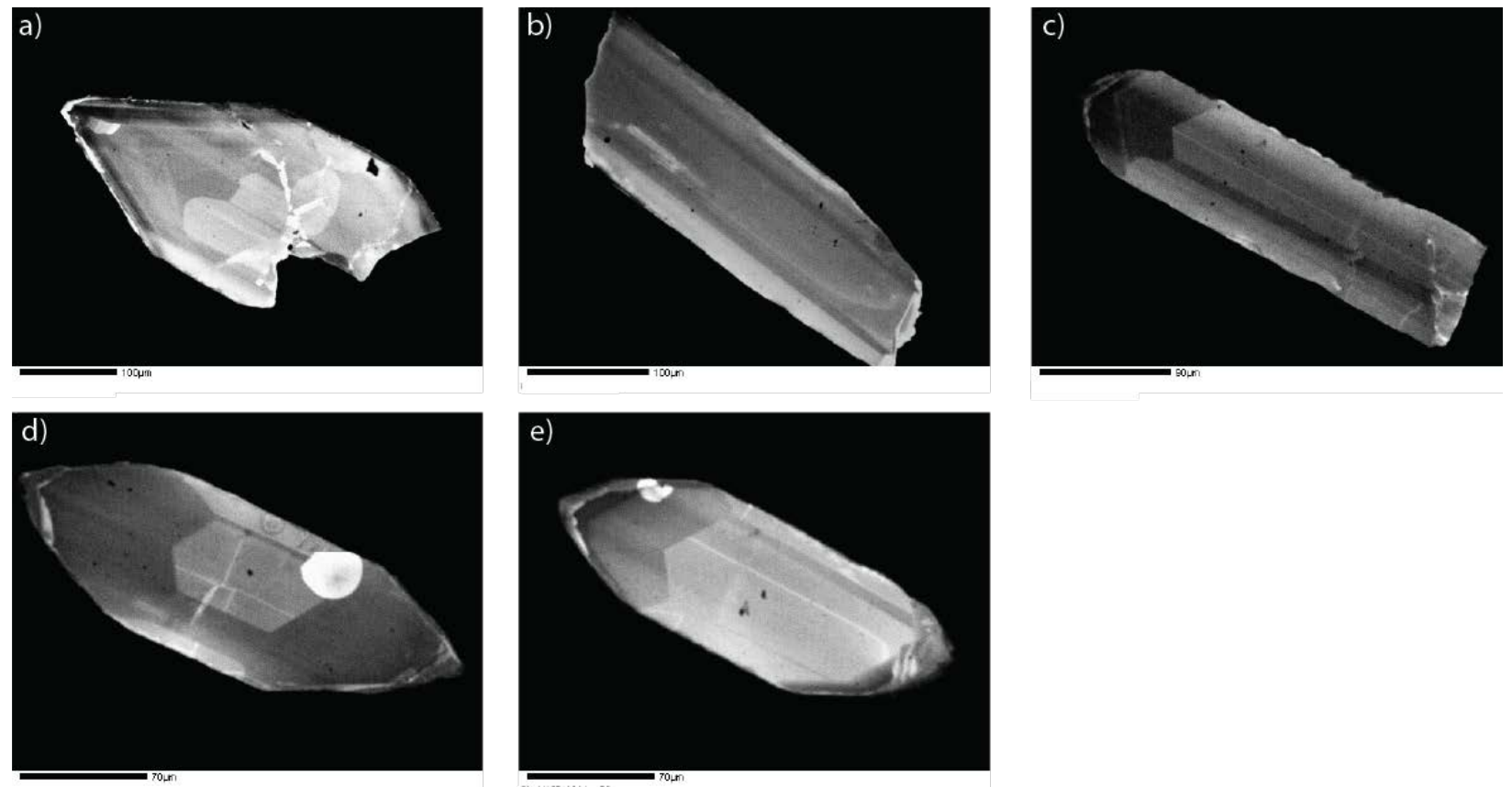

Figure 2I: CL images of dated zircons from sample AKCP-121A. Asterisk indicates dated grain. a) zL4* b) zM4* c) zS1* d) zS2* e) zS3*. AKCP-121A was collected from a $1 \mathrm{~m}$ thick hornblende-rich quartz diorite sheet intruded into a larger heterogeneous mafic layer. Zircons from AKCP-121A are clear, colorless, euhedral equant crystals. CL images of dated and representative crystals show oscillatory zoned rims surrounding light-colored cores. 

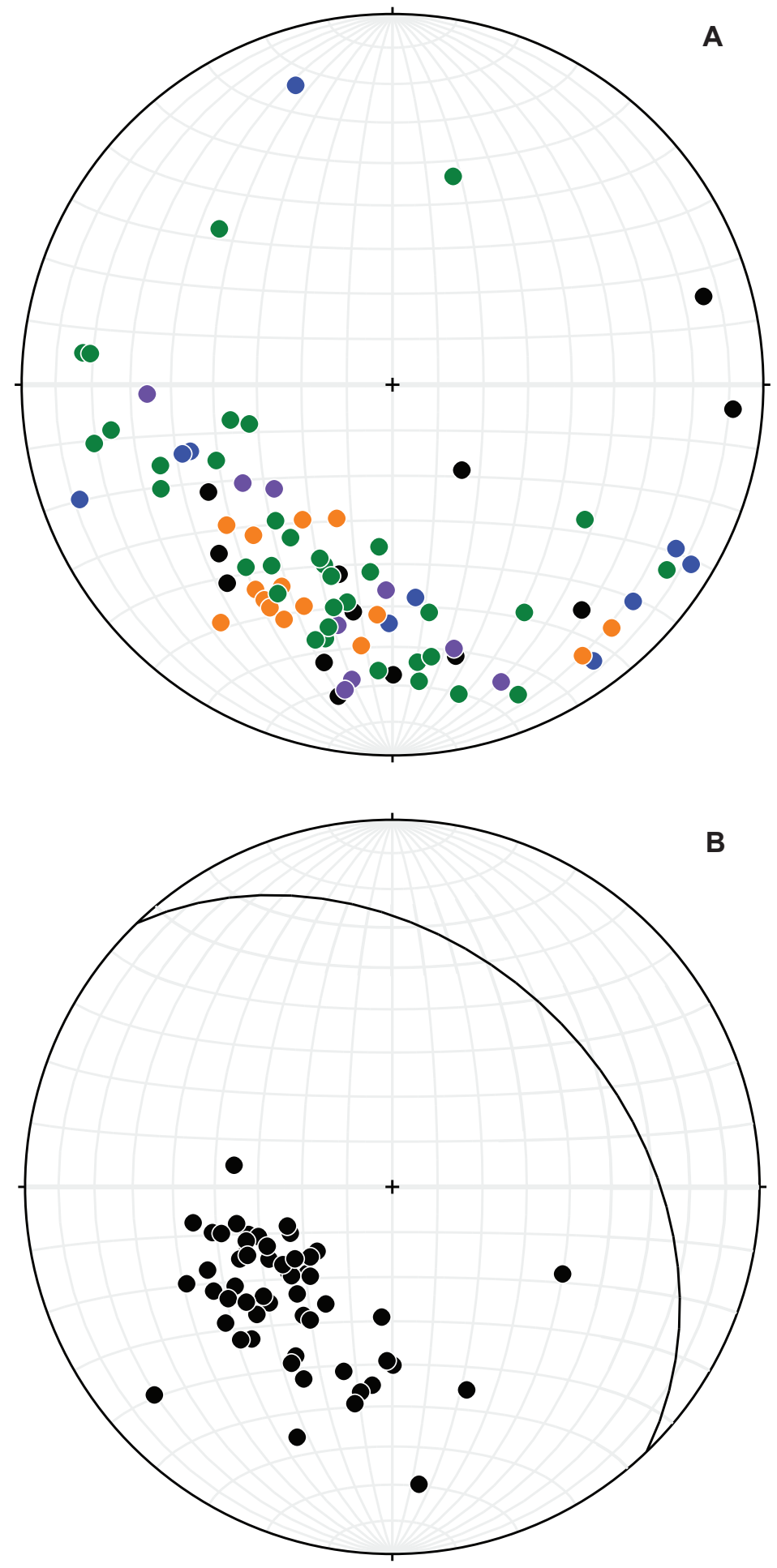

Figure S3. Stereonets from Stereonet 7 (Allmendinger, 2011). (A) Dike orientations $(n-=86)$ from the Tenpeak pluton sheeted zone. The following dikes are included strongly foliated rocks that be rafts of Napeequa metavolcanic (green), muscovite-bearing felsic dikes (purple), felsic dikes (black), strongly foliated, fine-grained dikes (red), and hybridized dikes (blue), and other igneous dikes (orange).

(B) Measured magmatic foliations and sheet contacts $(n=55)$ that were generally parallel to magmatic foliation. The principle orientation is $316 / 36$. 